(2) Open Access Full Text Article

\title{
Prevalence and relationship between major depressive disorder and lung cancer: a cross-sectional study
}

This article was published in the following Dove Press journal:

OncoTargets and Therapy

27 May 2014

Number of times this article has been viewed

Benchalak Maneeton'

Narong Maneeton'

Jirayu Reungyos'

Suthi Intaprasert'

Samornsri Leelarphat'

Sumitra Thongprasert ${ }^{2}$

'Department of Psychiatry,

${ }^{2}$ Department of Medicine, Faculty

of Medicine, Chiang Mai University,

Chiang Mai, Thailand
Correspondence: Narong Maneeton Department of Psychiatry, Faculty of Medicine, Chiang Mai University, Amphur Muang, Chiang Mai 50200,

Thailand

Tel +66 53945422

Fax $+6653217 \quad 144$

Email narong.m@cmu.ac.th
Objective: The aims of this study were to estimate the prevalence and examine the factors associated with major depressive disorder (MDD) in lung cancer patients.

Materials and methods: This cross-sectional study was carried out in the oncology clinic of the University Hospital, Chiang Mai University, Thailand. Patients with all stages of lung cancer were included in this study. Demographic data of eligible patients were gathered. The Mini-International Neuropsychiatric Interview, Thai version 5.0.0 was used to identify MDD. The Thai version of the Personal Health Questionnaire Depression Scale was used to assess depression severity.

Results: A total of 146 lung cancer patients from the outpatient clinic from July to December 2012 were approached. The 104 patients were included and analyzed in this study. Based on the Mini-International Neuropsychiatric Interview, 14.4\% of them were defined as having MDD. Multiple linear regression analysis revealed that Chalder Fatigue Scale, Functional Assessment of Cancer Therapy - Lung, and Pittsburgh Sleep Quality Index scores were significantly correlated with MDD in lung cancer patients.

Conclusion: The results suggest that MDD is more prevalent in lung cancer patients. In addition, fatigue, poor quality of life, and sleep disturbance may increase associated MDD. Because of the small sample size, further studies should be conducted to confirm these results.

Keywords: lung cancer, major depressive disorder, prevalence

\section{Introduction}

Patients with lung cancer usually experience distress from physical signs and symptoms, such as coughing, wheezing, and shortness of breath. Weight loss, insomnia from physical symptoms, fatigue, and chest pain are common, with most patients having multiple distressing symptoms. Any combination of treatments in practice, such as chemotherapy, surgery, or radiation, can cause distress from the adverse effects of the treatment. These clinical symptoms can disturb quality of life and cause depressive disorder. Lung cancer is often an aggressive disease, causing patients to face their own mortality and see their families starting to grieve at the patient's suffering and the prospect of the patient dying.

Among individuals with malignancy, lung cancer patients encounter a greater risk of depression development. ${ }^{1}$ A previous study suggests that the prevalence rate of depression, measured by the Hospital Anxiety and Depression Scale data and qualityof-life items from the Rotterdam Symptom Checklist, is as high as $33 \%$. $^{2}$ Additionally, a meta-analysis suggests that the pooled prevalence rates of depression in lung cancer patients are $11 \%-44 \% .{ }^{1}$ Since depression can negatively affect the treatment outcome 
of lung cancer, determining associated factors of depression in such patients may be beneficial.

A previous study also reported that the possible associated factors for depression in lung cancer patients included functional impairment, fatigue, and more severe symptoms. ${ }^{2}$ It is possible that educational attainment simply reflects patients being able to voice symptoms in a more articulate manner, which would imply more depressive suffering going unnoticed than we realize. Additionally, a recent study demonstrates that depression in lung cancer patients is related to neuroticism and coping style, including low fighting spirit, helplessness/hopelessness, and anxious preoccupation. ${ }^{3}$

Although interest in associated factors in cancer patients has increased among physicians and other health professionals, there are still few studies focusing on such associated factors influencing depression development, especially in major depressive disorder (MDD), in the lung cancer population. Additionally, previous studies have been carried out in Western countries; therefore, the use of those outcomes may be limited, due to the different culture. For this reason, we decided to conduct this study. The aim of the present study was to determine the prevalence of MDD and to identify associated factors for MDD development in lung cancer patients. We hypothesized that the prevalence rate of MDD in lung cancer would be higher than that of the general population, and that the development of MDD in those lung cancer patients would be associated with pain, fatigue, quality of life, and comorbidity.

\section{Materials and methods \\ Patients}

This study was cross-sectional. All lung cancer patients followed up in the oncology clinic of University Hospital, Chiang Mai University, Thailand were assessed and screened for eligibility to enter the study (July 2012-December 2012). Patients with all stages of lung cancer, aged 18 years or more, receiving any treatment (including specific anticancer, symptomatic and/or supportive therapies), and verbally communicating were included in this study. In the case of uneducated patients, we collected the data by interviewing them, and also gathered those details from their relatives. However, patients who did not cooperate due to impairment of consciousness or severe psychiatric symptoms were excluded from the study. Additionally, patients with disorders of the central nervous system were excluded. Eligible patients were provided details about the assessment procedure (see Figure 1). This study was approved by the

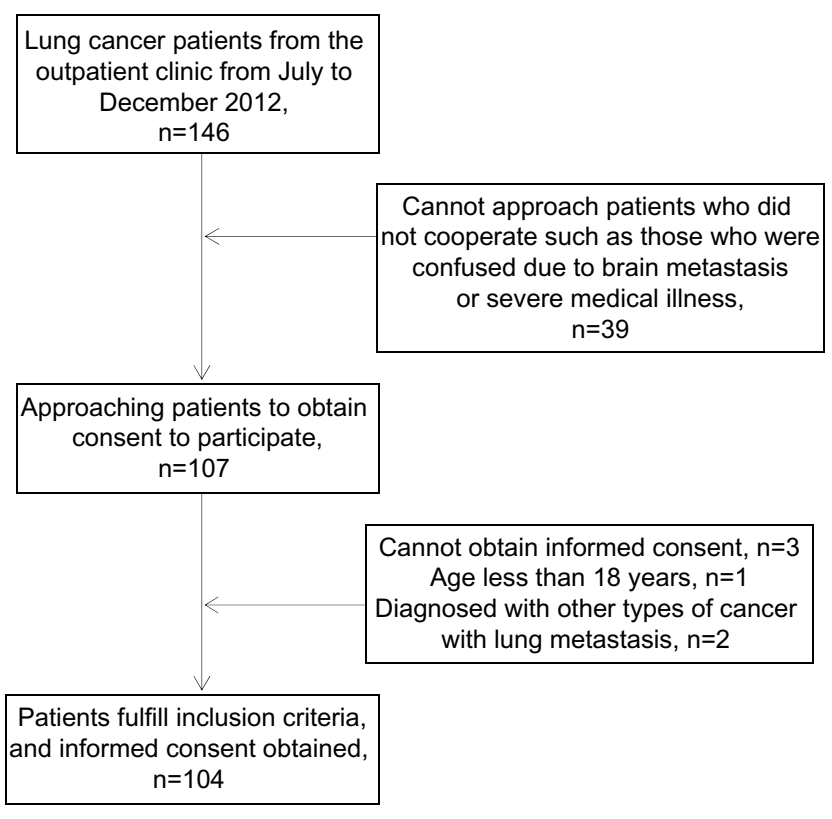

Figure I Flow diagram of study enrollment and completion for lung cancer patients.

medical ethical committee of Chiang Mai University, and all subjects provided informed consent.

\section{Assessment}

Baseline characteristics of eligible patients were gathered. The depression module of the Mini-International Neuropsychiatric Interview (MINI), Thai version 5.0.0, a short structured diagnostic interview, ${ }^{4}$ was applied to identify major depressive disorder. Additionally, the Thai version of the Personal Health Questionnaire Depression Scale (PHQ-9), a reliable and validated measure, ${ }^{5}$ was used for evaluating depression severity. As per previous research, associated factors in lung cancer with depression are the social support system, ${ }^{6}$ performance status, ${ }^{3}$ and physical burden; ${ }^{7}$ therefore, the Functional Assessment of Cancer Therapy - Lung (FACT-L), ${ }^{8}$ including physical, social, family, emotional, and functional well-being, and additional concern subscales, was used for evaluating such patients. This instrument is a valid, comprehensive, relatively brief assessment of quality of life with a specific emphasis on lung cancer symptoms. It also performs as predicted in relation to change in clinical status over time.

High disease burden, reported as another associated factor, ${ }^{9}$ was assessed by using the Charlson Comorbidity Index, evaluating the severity of physical illness. ${ }^{10}$ Sleep disturbance, determined as an associated factor of depression in these patients, ${ }^{11}$ was assessed by using the Pittsburgh Sleep Quality Index (PSQI). ${ }^{12}$ Pain and fatigue, which have 
a significant impact on patients' quality of life, ${ }^{13}$ were evaluated by using the visual analog scale (VAS) for pain and the eleven-item Chalder Fatigue Scale, addressing physical and mental fatigue, ${ }^{14}$ respectively. Remaining related factors, such as younger age $\mathrm{e}^{7,9}$ and presence of metastatic disease, ${ }^{15}$ were also recorded.

\section{Statistical analysis}

Since the expected prevalence rate of MDD in lung cancer patients was $10 \%,{ }^{16}$ the sample size with a $95 \%$ confidence interval was 96 for this study. Therefore, we planned to include 100 participants in the study. Descriptive analysis of sociodemographic data and clinical variables was performed. In this study, depression was assigned as the dependent variable. The $t$-test or Mann-Whitney $U$ test (for continuous variables) and Fisher's exact test or $\chi^{2}$ test (for categorical variables) were applied for evaluating the significant association (contingency) of independent variables between the depressive and nondepressive groups. Multivariate analysis was performed by using the multiple linear regression model. All independent variables that had statistical significance at the bivariate level $(P<0.200)$ were eligible and taken into the analysis. Authors then developed a final model that consisted of patient characteristics, considered as included variables independently correlated with severity of depressive disorder in the lung cancer patients. All analysis was performed by using SPSS (version 17; SPSS, Chicago, IL, USA).

\section{Results}

A total of 146 lung cancer patients from the outpatient clinic from July to December 2012 were approached. Of 107 lung cancer patients, $104(97.2 \%)$ patients were included and analyzed in this study. Three patients $(0.03 \%)$ were excluded due to not meeting the inclusion criteria (a male patient was 17 years old, and the other two patients were diagnosed with another type of cancer with lung metastasis). Fifty-four included patients were male. The mean age (standard deviation) of these patients was 61.5 (9.4) years, and 39.4\% of them were 65 years or older. Seven patients $(6.7 \%)$ were not educated, and $67.3 \%$ had $1-6$ years of education. Most participants (77.9\%) were married, and 16.3\% were widowed. Almost all patients (99\%) had support from family members or relatives. Unfortunately, the majority of patients (57.7\%) were unemployed; therefore, the average income was low: $70.2 \%$ of patients had an annual income of US $\$ 2,000$ or less, and $45.2 \%$ of patients had debts. Mean (standard deviation) duration of lung cancer was 16.4 (18.7) months, and stages of cancer were quite advanced, mostly categorized as stage $3(20.2 \%)$ and stage $4(69.2 \%)$.

Before enrollment, one patient (non-MDD versus MDD, 1:0) received surgical treatment, four patients (non-MDD versus MDD, 3:1) received radiotherapy, and one patient (non-MDD versus MDD, 1:0) received both surgical treatment and radiotherapy. Of 104 included patients, $100(96.2 \%)$ patients were receiving chemotherapy when they were assessed, and the rest (3.8\%) had completed chemotherapy before being included in this study (see Table 1).

Based on the MINI, Thai version 5.0.0, 14.4\% of patients were defined as having MDD. Table 1 compares the basic characteristics between the MDD and non-MDD groups of the lung cancer patients. Comparison of the two groups on age, sex, education, marital status, having a support system, occupation, annual income, and debt showed no significant differences. Based on severity of malignancy, there were no significant differences either in the two groups in terms of disease duration, stage of cancer, number of treatment methods, and line of treatment. Additionally, comorbid medical illness, as measured by the Charlson Comorbidity Index, was not significantly different between the groups. Fatigue $(P<0.001)$, assessed by the Chalder Fatigue Scale, quality of life $(P<0.001)$, measured by the FACT-L, pain $(P=0.008)$, measured by the VAS for pain, and quality of sleep $(P<0.001)$, determined by the PSQI, were significantly different between the groups $(P<0.05)$. As a result, these factors were included in multiple linear regression analysis as covariables. Moreover, other factors that had significant differences $(P<0.200)$ were included in the analysis (age, occupation, line of treatment, Charlson Comorbidity Index score). The findings suggested that the Chalder Fatigue Scale, the FACT-L, and the PSQI scores were significant predictors of severity of MDD in lung cancer patients (adjusted $R^{2}=0.682$, standard error of the estimate $=3.704$, Durbin - Watson statistic $=1.857)($ see Table 2).

\section{Discussion}

The present study demonstrates that the prevalence of MDD in lung cancer patients is quite high. The point prevalence of MDD in our patients was $14.4 \%$. Additionally, fatigue, poor quality of life, and sleep disturbance appear to be related in the development of MDD in lung cancer patients.

As is known, the prevalence of depression is high and one of the most common mental illnesses in patients with 
Table I Demographic and clinical characteristics of lung cancer patients

\begin{tabular}{|c|c|c|c|c|}
\hline $\begin{array}{l}\text { Characteristics, } \mathbf{n}(\%) / \\
\text { mean } \pm \text { SD }\end{array}$ & $\begin{array}{l}\text { All } \\
(n=104)\end{array}$ & $\begin{array}{l}\text { Current MDD } \\
(n=15)\end{array}$ & $\begin{array}{l}\text { Non-MDD } \\
(n=89)\end{array}$ & $P$-value \\
\hline Age, years & $61.5 \pm 9.4$ & $57.8 \pm 10.6$ & $62.1 \pm 9.1$ & 0.104 \\
\hline Male & $54(51.9 \%)$ & $8(53.3 \%)$ & $46(51.7 \%)$ & 0.906 \\
\hline Education, years & & & & 0.969 \\
\hline None & $7(6.7 \%)$ & I (6.7\%) & $6(6.7 \%)$ & \\
\hline $1-6$ & $70(67.3 \%)$ & $10(66.7 \%)$ & $60(67.4 \%)$ & \\
\hline $7-9$ & $3(2.9 \%)$ & 0 & $3(3.4 \%)$ & \\
\hline $10-12$ & $5(4.8 \%)$ & I (6.7\%) & $4(4.5 \%)$ & \\
\hline$\geq 13$ & $19(18.3 \%)$ & $3(20.0 \%)$ & $16(18.0 \%)$ & \\
\hline Marital status & & & & 1.000 \\
\hline Single & $4(3.8 \%)$ & 0 & $4(4.5 \%)$ & \\
\hline Married & $81(77.9 \%)$ & $13(86.7 \%)$ & 68 (76.4\%) & \\
\hline Separated & $2(1.9 \%)$ & 0 & $2(2.2 \%)$ & \\
\hline Widowed & $17(16.3 \%)$ & $2(13.3 \%)$ & $15(16.9 \%)$ & \\
\hline Support & & & & 1.000 \\
\hline No & I (I.0\%) & 0 & I (I.I\%) & \\
\hline Yes & $103(99.0 \%)$ & $15(100 \%)$ & $88(98.9 \%)$ & \\
\hline Occupation & & & & 0.139 \\
\hline Unemployed & $60(57.7 \%)$ & $10(66.7 \%)$ & $50(56.2 \%)$ & \\
\hline Employee & $13(12.5 \%)$ & $4(26.7 \%)$ & $9(10.1 \%)$ & \\
\hline Owner & $6(5.8 \%)$ & 0 & $6(6.7 \%)$ & \\
\hline Government service & $5(4.8 \%)$ & I (6.7\%) & $4(4.5 \%)$ & \\
\hline State enterprise or private & $2(1.9 \%)$ & 0 & $2(22.2 \%)$ & \\
\hline Others & $18(17.3 \%)$ & 0 & $18(20.2 \%)$ & \\
\hline Annual income $(U S \$)(\$ 1=B 30)$ & & & & 0.955 \\
\hline$\leq 2,000$ & $73(70.2 \%)$ & $12(80.0 \%)$ & $6 \mathrm{I}(68.5 \%)$ & \\
\hline $2,00 I-4,000$ & $12(11.5 \%)$ & I (67.0\%) & II (I2.4\%) & \\
\hline $4,00 I-6,000$ & $5(4.8 \%)$ & 0 & $5(5.6 \%)$ & \\
\hline$\geq 6,000$ & 14 (13.5\%) & $2(13.3 \%)$ & $12(13.5 \%)$ & \\
\hline Debt & & & & 0.318 \\
\hline Yes & 47 (45.2\%) & $5(33.3 \%)$ & $42(47.2 \%)$ & \\
\hline No & $57(54.8 \%)$ & $10(66.7 \%)$ & $47(52.8 \%)$ & \\
\hline Duration of disease, months & $16.4 \pm 18.7$ & $19.5 \pm 22.1$ & $15.8 \pm 18.1$ & 0.450 \\
\hline Stage of cancer & & & & 1.000 \\
\hline 1 & $5(4.8 \%)$ & 0 & $5(5.6 \%)$ & \\
\hline II & $6(5.8 \%)$ & I (6.7\%) & $5(5.6 \%)$ & \\
\hline III & $2 \mathrm{I}(20.2 \%)$ & $3(20.0 \%)$ & $18(20.2 \%)$ & \\
\hline IV & 72 (69.2\%) & II (73.3\%) & $6 \mathrm{I}(68.5 \%)$ & \\
\hline Number of treatment method(s) & & & & 0.412 \\
\hline One & $50(48.1 \%)$ & 7 (46.7\%) & $43(48.3 \%)$ & \\
\hline Two & $43(41.3 \%)$ & $5(33.3 \%)$ & $38(42.7 \%)$ & \\
\hline Three & II (I0.6\%) & $3(20.0 \%)$ & $8(9.0 \%)$ & \\
\hline Current line of chemotherapy & & & & 0.107 \\
\hline First-line & $34(32.7 \%)$ & $2(13.3 \%)$ & $32(36.0 \%)$ & \\
\hline Before second-line & $27(26.0 \%)$ & $4(26.7 \%)$ & $23(25.8 \%)$ & \\
\hline Second-line & $19(18.3 \%)$ & $5(33.3 \%)$ & $14(15.7 \%)$ & \\
\hline Before third-line & $15(14.4 \%)$ & $2(13.3 \%)$ & $13(14.6 \%)$ & \\
\hline Third-line & $5(4.8 \%)$ & 0 & $5(5.6 \%)$ & \\
\hline Completed & $4(3.8 \%)$ & $2(13.3 \%)$ & $2(2.2 \%)$ & \\
\hline Charlson Comorbidity Index scores & $7.0 \pm 2.4$ & $7.7 \pm 2.7$ & $6.9 \pm 2.3$ & 0.191 \\
\hline Chalder Fatigue Scale scores & $18.4 \pm 5.9$ & $25.3 \pm 4.5$ & $17.2 \pm 5.3$ & $<0.001$ \\
\hline \multicolumn{5}{|l|}{ FACT-L scores } \\
\hline Physical well-being & $19.9 \pm 6.2$ & $12.3 \pm 5.3$ & $2 I . I \pm 5.4$ & $<0.001$ \\
\hline Social/family well-being & $21.1 \pm 4.3$ & $19.2 \pm 4.5$ & $21.4 \pm 4.2$ & 0.112 \\
\hline Emotional well-being & $19.9 \pm 3.8$ & $15.9 \pm 4.3$ & $20.6 \pm 3.3$ & $<0.001$ \\
\hline Functional well-being & $17.6 \pm 6.0$ & $1 \mathrm{I} .4 \pm 4.7$ & $18.6 \pm 5.6$ & $<0.001$ \\
\hline
\end{tabular}


Table I (Continued)

\begin{tabular}{|c|c|c|c|c|}
\hline $\begin{array}{l}\text { Characteristics, } n(\%) / \\
\text { mean } \pm \text { SD }\end{array}$ & $\begin{array}{l}\text { All } \\
(n=104)\end{array}$ & $\begin{array}{l}\text { Current MDD } \\
(n=15)\end{array}$ & $\begin{array}{l}\text { Non-MDD } \\
(\mathrm{n}=89)\end{array}$ & $P$-value \\
\hline Additional concerns & $20.1 \pm 5.3$ & $13.8 \pm 4.4$ & $21.2 \pm 4.7$ & $<0.001$ \\
\hline Sum of FACT-L scores & $98.6 \pm 19.2$ & $72.7 \pm 15.4$ & $102.9 \pm 16.1$ & $<0.001$ \\
\hline VAS for pain scores & $2.9 \pm 2.8$ & $4.7 \pm 2.7$ & $2.6 \pm 2.7$ & 0.008 \\
\hline PSQI scores & $6.3 \pm 4.4$ & II $.5 \pm 4.5$ & $5.4 \pm 3.8$ & $<0.001$ \\
\hline PHQ-9 scores & $6.3 \pm 6.6$ & $18.6 \pm 4.9$ & $4.2 \pm 4.0$ & $<0.001$ \\
\hline
\end{tabular}

Abbreviations: SD, standard deviation; MDD, major depressive disorder; FACT-L, Functional Assessment of Cancer Therapy - Lung; VAS, visual analog scale; PSQI, Pittsburgh Sleep Quality Index; PHQ, Patient Health Questionnaire.

malignancy. ${ }^{17,18}$ Like the present findings, previous research suggested that the prevalence of self-reported depression in pretreatment lung cancer patients was up to $33 \%{ }^{2}$ Additionally, previous evidence also reported that up to $16 \%$ of lung cancer patients had symptoms of major depression at first hospital visit. ${ }^{15,19}$ Since there is more prevalence of depression in this population, regular evaluation and optimal treatment for depressive disorder in those patients may be beneficial.

Recently, there has been raised concern regarding quality of life in patients with chronic disease. Lung cancer patients, particularly those in an advanced stage, suffer from poor physical condition, which often negatively affects their quality of life..$^{13}$ A recent study conducted on non-small-cell lung cancer (NSCLC) patients suggested that lung cancer with stage IV disease, higher line of treatment, and more progressive disease substantially impacted patient quality of life. ${ }^{20}$ Poor quality of life may cause various psychiatric disorders, including depression. Like the present findings, a recent study of NSCLC patients reported that depression was associated with health-related quality of life. ${ }^{21}$ This phenomenon may explain how poor quality of life can cause psychological stressors, which may precipitate depression. Since poor quality of life is associated with depression, particularly in MDD,

Table 2 Multiple linear regression analysis of predictors for major depressive disorder in lung cancer patients

\begin{tabular}{lllll}
\hline Variables & $\begin{array}{l}\text { Multiple linear } \\
\text { regression } \\
\text { coefficient }(\boldsymbol{\beta})\end{array}$ & SE $(\boldsymbol{\beta})$ & $\boldsymbol{t}$ & P-value \\
\hline $\begin{array}{l}\text { Chalder Fatigue } \\
\text { Scale scores }\end{array}$ & 0.308 & 0.083 & 3.699 & $<0.001$ \\
FACT-L score & -0.141 & 0.027 & -5.183 & $<0.00 \mathrm{I}$ \\
PSQI score & 0.407 & 0.108 & 3.757 & $<0.00 \mathrm{I}$ \\
Constant & $\mathrm{I} 1.964$ & 3.871 & 3.091 & 0.003 \\
\hline
\end{tabular}

Note: PHQ-9 score $=0.308$ (Chalder Fatigue Scale score) -0.14 I (FACT-L score) + 0.407 (PSQI score) + II.964.

Abbreviations: SE, standard error; FACT-L, Functional Assessment of Cancer Therapy - Lung; PSQI, Pittsburgh Sleep Quality Index; PHQ, Patient Health Questionnaire. any method or treatment for improving patient quality of life may reduce symptoms of depression.

Recent evidence suggests that up to $70 \%$ of elderly cancer patients experience fatigue. ${ }^{22}$ Additionally, a recent systematic review suggested that the prevalence of fatigue in Hodgkin lymphoma patients is between $11 \%$ and $76 \%$, while the prevalence in the general population is only $10 \% .{ }^{23}$ This symptom is also often seen in lung cancer patients. A previous study reported that the prevalence of fatigue was $15 \% .^{24}$ As it affects patients' quality of life, ${ }^{22}$ fatigue may cause a mental illness in these patients.

The relationship between cancer-related fatigue and depression has been reported. A previous study reported that depression, as measured by the Brief Symptom Inventory depression subscale, correlated with fatigue, measured by the FACT fatigue subscale. ${ }^{25}$ In addition, this association is also seen in lung cancer patients. Like the present finding, previous evidence also suggests that Hospital Anxiety and Depression scale score is correlated with fatigue in lung cancer patients. ${ }^{26}$ Generally, fatigue is one of the depressive symptoms that may explain the association. Since fatigue is associated with depression, appropriate evaluation and treatment may be of benefit.

Insomnia is a common symptom in cancer patients, and its prevalence is up to $50 \% .^{27,28}$ Recent evidence suggests that disturbed sleep is one of the top four complaints of lung cancer surgery patients. ${ }^{29}$ Since insomnia can increase cancer symptoms and affect quality of life,${ }^{30}$ it may increase the risk of depressive disorder in cancer, including lung cancer. Previous evidence suggests that sleep disturbance is able to increase frequency of depression and worsen wellbeing in patients with advanced disease. ${ }^{31}$ Like the present study, a previous study reported that significantly high global PSQI scores in lung cancer patients were found in depressive groups. ${ }^{32}$ Similar to fatigue, sleep disturbance is often found in depressed patients. Its association, therefore, may be explained by this mechanism. Systematic screening and appropriate treatment for insomnia may be useful. 
There were some limitations of the present study. Firstly, the outcomes of this study were as a result of a small-population study. However, further study in a large population should be carried out to confirm this finding. Secondly, since all included subjects were follow-up lung cancer patients, their prevalence and associated factors for developing MDD may differ from newly diagnosed patients. Generalization of this finding to the first diagnosed setting should be done cautiously. Thirdly, sadness and hopelessness are included in the emotional subscale of the FACT-L, and they are also included in the PHQ-9. Similarly, sleep disturbance, measured by the PSQI, can be a symptom of depression. Therefore, interpretation of these associations should be approached with caution. Fourthly, personality traits, known as another associated factor of depression in lung cancer, ${ }^{3}$ were not examined in this study. Fifthly, since this study was conducted in the Thai population, there were some cultural differences possibly influencing the development of MDD in lung cancer patients. For instance, a previous study in lung cancer patients treated with surgical treatment suggests that social support relates to depression in the first 3 months after surgery. ${ }^{6}$ Unfortunately, the association was not found in this study since most of the patients in both groups had family support. Therefore, application of these findings in other countries should be done cautiously. Finally, most included patients had more advanced lung cancer; therefore, this may have affected the prevalence of MDD. Applying that prevalence in a population with lesser stages of lung cancer should be done carefully.

In summary, the prevalence of MDD is relatively high in lung cancer patients. Poor quality of life, fatigue, and sleep disturbance correlate with MDD in these patients. Therefore, routine screening, treating, and preventing, if possible, these associated factors in clinical settings may reduce the incidence of MDD in these patients.

\section{Acknowledgments}

We thank the Faculty of Medicine, Chiang Mai University, which provided the grant funding for this study. We thank Professor Stephen D Martin, MBBS, MRCPsych, MEWI, Brandon Lane Neuropsychiatry Clinic, Durham, UK for his substantial help with this project.

\section{Disclosure}

The authors report no conflicts of interest in this work.

\section{References}

1. Massie MJ. Prevalence of depression in patients with cancer. J Natl Cancer Inst Monogr. 2004;(32):57-71.
2. Hopwood P, Stephens RJ. Depression in patients with lung cancer: prevalence and risk factors derived from quality-of-life data. $J$ Clin Oncol. 2000;18(4):893-903.

3. Shimizu K, Nakaya N, Saito-Nakaya K, et al. Clinical biopsychosocial risk factors for depression in lung cancer patients: a comprehensive analysis using data from the Lung Cancer Database Project. Ann Oncol. 2012;23(8):1973-1979.

4. Kittirattanapaiboon P, Khamwongpin M. The validity of the Mini International Neuropsychiatric Interview (MINI) - Thai version. J Ment Health Thailand. 2005;13(3):125-135.

5. Lotrakul M, Sumrithe S, Saipanish R. Reliability and validity of the Thai version of the PHQ-9. BMC Psychiatry. 2008;8:46.

6. Uchitomi Y, Mikami I, Kugaya A, et al. Depression after successful treatment for nonsmall cell lung carcinoma. Cancer. 2000;89(5): $1172-1179$.

7. Lo C, Zimmermann C, Rydall A, et al. Longitudinal study of depressive symptoms in patients with metastatic gastrointestinal and lung cancer. J Clin Oncol. 2010;28(18):3084-3089.

8. Cella DF, Bonomi AE, Lloyd SR, Tulsky DS, Kaplan E, Bonomi P. Reliability and validity of the Functional Assessment of Cancer Therapy-Lung (FACT-L) quality of life instrument. Lung Cancer. 1995;12(3):199-220.

9. Rodin G, Lo C, Mikulincer M, Donner A, Gagliese L, Zimmermann C. Pathways to distress: the multiple determinants of depression, hopelessness, and the desire for hastened death in metastatic cancer patients. Soc Sci Med. 2009;68(3):562-569.

10. Birim O, Kappetein AP, Bogers AJ. Charlson comorbidity index as a predictor of long-term outcome after surgery for nonsmall cell lung cancer. Eur J Cardiothorac Surg. 2005;28(5):759-762.

11. Du-Quiton J, Wood PA, Burch JB, et al. Actigraphic assessment of daily sleep-activity pattern abnormalities reflects self-assessed depression and anxiety in outpatients with advanced non-small cell lung cancer. Psychooncology. 2010;19(2):180-189.

12. Backhaus J, Junghanns K, Broocks A, Riemann D, Hohagen F. Test-retest reliability and validity of the Pittsburgh Sleep Quality Index in primary insomnia. J Psychosom Res. 2002;53(3): 737-740.

13. Iyer S, Taylor-Stokes G, Roughley A. Symptom burden and quality of life in advanced non-small cell lung cancer patients in France and Germany. Lung Cancer. 2013;81(2):288-293.

14. Morriss RK, Wearden AJ, Mullis R. Exploring the validity of the Chalder Fatigue scale in chronic fatigue syndrome. J Psychosom Res. 1998;45(5):411-417.

15. Hughes JE. Depressive illness and lung cancer. I. Depression before diagnosis. Eur J Surg Oncol. 1985;11(1):15-20.

16. Pirl WF, Temel JS, Billings A, et al. Depression after diagnosis of advanced non-small cell lung cancer and survival: a pilot study. Psychosomatics. 2008;49(3):218-224.

17. Krebber AM, Buffart LM, Kleijn G, et al. Prevalence of depression in cancer patients: a meta-analysis of diagnostic interviews and self-report instruments. Psychooncology. 2014;23(2):121-130.

18. Hong JS, Tian J. Prevalence of anxiety and depression and their risk factors in Chinese cancer patients. Support Care Cancer. 2014;22(2): 453-459.

19. Hamann HA, Lee JW, Schiller JH, et al. Clinician perceptions of care difficulty, quality of life, and symptom reports for lung cancer patients: an analysis from the Symptom Outcomes and Practice Patterns (SOAPP) study. J Thorac Oncol. 2013;8(12):1474-1483.

20. Chouaid C, Agulnik J, Goker E, et al. Health-related quality of life and utility in patients with advanced non-small-cell lung cancer: a prospective cross-sectional patient survey in a real-world setting. $J$ Thorac Oncol. 2013;8(8):997-1003.

21. Arrieta O, Angulo LP, Núñez-Valencia C, et al. Association of depression and anxiety on quality of life, treatment adherence, and prognosis in patients with advanced non-small cell lung cancer. Ann Surg Oncol. 2013;20(6):1941-1948. 
22. Giacalone A, Quitadamo D, Zanet E, Berretta M, Spina M, Tirelli U. Cancer-related fatigue in the elderly. Support Care Cancer. 2013; 21(10):2899-2911.

23. Daniels LA, Oerlemans S, Krol AD, van de Poll-Franse LV, Creutzberg CL. Persisting fatigue in Hodgkin lymphoma survivors: a systematic review. Ann Hematol. 2013;92(8):1023-1032.

24. Cheville AL, Novotny PJ, Sloan JA, et al. Fatigue, dyspnea, and cough comprise a persistent symptom cluster up to five years after diagnosis with lung cancer. J Pain Symptom Manage. 2011;42(2):202-212.

25. Tchekmedyian NS, Kallich J, McDermott A, Fayers P, Erder MH. The relationship between psychologic distress and cancer-related fatigue. Cancer. 2003;98(1):198-203.

26. Brown DJ, McMillan DC, Milroy R. The correlation between fatigue, physical function, the systemic inflammatory response, and psychological distress in patients with advanced lung cancer. Cancer. 2005;103(2):377-382.

27. Davidson JR, MacLean AW, Brundage MD, Schulze K. Sleep disturbance in cancer patients. Soc Sci Med. 2002;54(9):1309-1321.
28. O’Donnell JF. Insomnia in cancer patients. Clin Cornerstone. 2004; 6 Suppl 1D:S6-S14.

29. Lin S, Chen Y, Yang L, Zhou J. Pain, fatigue, disturbed sleep and distress comprised a symptom cluster that related to quality of life and functional status of lung cancer surgery patients. J Clin Nurs. 2013;22(9-10): 1281-1290.

30. Induru RR, Walsh D. Cancer-related insomnia. Am J Hosp Palliat Care. Epub October 17, 2013.

31. Delgado-Guay M, Yennurajalingam S, Parsons H, Palmer JL, Bruera E. Association between self-reported sleep disturbance and other symptoms in patients with advanced cancer. J Pain Symptom Manage. 2011; 41(5):819-827.

32. Van Onselen C, Dunn LB, Lee K, et al. Relationship between mood disturbance and sleep quality in oncology outpatients at the initiation of radiation therapy. Eur J Oncol Nurs. 2010;14(5):373-379.

\section{Publish your work in this journal}

OncoTargets and Therapy is an international, peer-reviewed, open access journal focusing on the pathological basis of all cancers, potential targets for therapy and treatment protocols employed to improve the management of cancer patients. The journal also focuses on the impact of management programs and new therapeutic agents and protocols on

\section{Dovepress}

patient perspectives such as quality of life, adherence and satisfaction. The manuscript management system is completely online and includes a very quick and fair peer-review system, which is all easy to use. Visit http://www.dovepress.com/testimonials.php to read real quotes from published authors. 